\title{
Pharmacological effects and behavioral interventions on memory consolidation and reconsolidation
}

\author{
C.M. Baratti ${ }^{*}$ M.M. Boccia* and M.G. Blake* \\ Laboratorio de Neurofarmacología de los Procesos de Memoria, Cátedra de Farmacología, Facultad de \\ Farmacia y Bioquímica, Universidad de Buenos Aires, Buenos Aires, Argentina
}

Correspondence to: C.M. Baratti, Laboratorio de Neurofarmacología de los Procesos de Memoria, Cátedra de Farmacología, Facultad de Farmacia y Bioquímica, Universidad de Buenos Aires, Junín, 956, 5th floor, C1113AAD Buenos Aires, Argentina

Fax: +5411-4964-8266. E-mail: cbaratti@ffyb.uba.ar

\begin{abstract}
In this article, we will review some behavioral, pharmacological and neurochemical studies from our laboratory on mice, which might contribute to our understanding of the complex processes of memory consolidation and reconsolidation. We discuss the post-training (memory consolidation) and post-reactivation (memory reconsolidation) effects of icv infusions of hemicholinium, a central inhibitor of acetylcholine synthesis, of intraperitoneal administration of L-NAME, a non-specific inhibitor of nitric oxide synthase, of intrahippocampal injections of an inhibitor of the transcription factor NF- $\mathrm{KB}$, and the exposure of mice to a new learning situation on retention performance of an inhibitory avoidance response. All treatments impair long-term memory consolidation and retrieval-induced memory processes different from extinction, probably in accordance with the "reconsolidation hypothesis".
\end{abstract}

Key words: Memory; Consolidation; Reconsolidation; Extinction; Inhibitory avoidance

${ }^{*}$ All authors contributed equally to this study.

Presented at the XXIII Annual Meeting of the Federação de Sociedades de Biologia Experimental, Águas de Lindóia, SP, Brazil, August 20-23, 2008.

Research supported by grants B028 SECyT-UBA to C.M. Baratti, B823 SECyT-UBA and PICT 38299 ANPCyT to M.M. Boccia. C.M. Baratti and M.M. Boccia are members of CONICET-Argentina.

Received August 4, 2008. Accepted January 5, 2009

\section{Introduction}

New memories are initially vulnerable to disruption but are progressively strengthened over time. The phenomenon is known as memory consolidation $(1,2)$, and requires protein synthesis ( 3 , but see also Ref. 4 ). It is traditionally accepted that once memory consolidation is completed memory becomes permanent (5). However, several studies have also shown that when a well-stabilized memory is reactivated (recalled) it again becomes sensitive to the same treatments that could affect memory consolidation when given after training. This new period of sensitivity is called memory reconsolidation (6).

We shall consider in this article the effects of intracerebroventricular (icv) infusions of hemicholinium (HC-3), a central inhibitor of acetylcholine (Ach) synthesis (7), of intraperitoneal administration of $\mathrm{N}^{\omega}$-nitro-L-arginine methyl ester (L-NAME), a non-specific inhibitor of nitric oxide synthase (NOS; 8), on post-training (memory consolidation) and post-reactivation (memory reconsolidation), and 
of intrahippocampal injections of an inhibitor of the transcription factor (nuclear factor $\kappa B, N F-\kappa B ; 9$ ) on retention performance of an inhibitory avoidance response in mice (10-13). We also will briefly discuss both the posttraining and the post-retrieval effects of the exposure of mice to a new learning experience (14). Some of the results reviewed here were previously presented at the XXII Reunião Anual da FESBE, Águas de Lindóia, SP, Brazil, 2007.

\section{Memory consolidation and reconsolidation: methodological issues}

The use of pharmacological and non-pharmacological treatments administered immediately or several times after training to impair or enhance memory provides a highly effective and extensively used method to study memory consolidation (2). This procedure is able to influence memory consolidation without affecting memory acquisition (learning), and reveals the time-dependent participation of neural systems and cellular processes, which enable lasting memories (2). One-trial step-down and step-through inhibitory ("passive or inactive") avoidance in rats and mice has long been a favorite model for pharmacological and neurochemical studies of memory consolidation (15).

To experimentally demonstrate memory reconsolidation, a particular memory must be first consolidated, and then reactivated (retrieved) during a specific retention test simultaneously with some form of manipulation (16). Finally, modifications of the original memory must be observed following a new retention test (16). A necessary criterion to consider an effect on memory reconsolidation is that the procedure employed with this purpose must be effective only following memory reactivation $(17,18)$. It is also necessary to demonstrate the post-retrieval timewindow susceptibility of the original consolidated memory following its retrieval, as well as the specificity for previously trained stimuli or context (16). On the other hand, it is well known that repeated retrieval without reinforcement leads to extinction of memories (19). On this basis, and considering that in the experimental protocols used to study memory reconsolidation the original and well-consolidated memory is reactivated (retrieved) under the influence of previous conditioned stimuli, but in the absence of the unconditioned ones (that is, without reinforcement), it is also necessary to analyze the potential development of an extinction phenomenon as an alternative explanation of the observed results (16). Under appropriate experimental conditions, extinguished memories can develop spontaneous recovery, reinstatement, saving and/or renewal (20). In addition, one of the most important findings that should be taken into account when interpreting a "reconsolidation result" is the relationship between the age of the reactivated memory and the susceptibility to be modified $(21,22)$. The precise conditions under which reconsolidation can be manipulated have been conceptualized as "boundary conditions of reconsolidation", and were recently reviewed by Alberini (22) and Tronson and Taylor (16).

Memory reconsolidation is frequently studied using Pavlovian fear conditioning (23). The results discussed here were obtained using an inhibitory ("passive or inactive") avoidance response (IAR). It is clear that the training procedures for these two behavioral paradigms have much in common. However, there are also important differences between fear conditioning and inhibitory avoidance procedures, which may have effects on the neural substrates involved, and may be crucial factors in determining how several pharmacological post-retrieval treatments affect memory reconsolidation (23).

In our studies, an intermediate foot shock level was used in experiments investigating memory consolidation processes. In contrast, a stronger foot shock was employed in experiments investigating reconsolidation in order to reduce the influence of extinction on retention performance (24). The question is whether, under appropriate experimental conditions, control over-reinforced mice can really extinguish or not their memory. If not, all interpretations about memory reconsolidation might be wrong. In fact, mice successfully develop extinction, although needing several successive extinction trials, and show spontaneous recovery (11). Furthermore, we were able to reinstate the avoidance behavior $(20,25)$ using a saving protocol (11).

Most memory reconsolidation studies show a blockade of the process, resulting in a poor performance of the experimental subjects used. These poor performance could be explained "theoretically" by two main reasons: a) a true blockade of the reconsolidation memory process; b) inaccessibility to the memory trace, frequently attributed to a retrieval deficit.

The latter could be explained by the development of an extinction phenomenon, or alternatively by the prevalence of neurohumoral and hormonal states at the time of retrieval (stress hormones, emotional states, etc.), as proposed years ago by Izquierdo (26) for different forms of post-training memory processing. On this basis, it is also necessary to assess the potential development of endogenous memory state dependency for post-retrieval treatments that could be affecting memory reconsolidation.

A basic behavioral procedure scheme used in our memory consolidation and reconsolidation studies is shown in Figure 1. 


\section{Pharmacological manipulation of memory consolidation and reconsolidation of an inhibitory avoidance response}

\section{Acetylcholine}

It is well known that endogenous Ach release is necessary for long-term memory consolidation (27). In this sense, we have demonstrated that icv infusions of $\mathrm{HC}-3$, a specific inhibitor of high-affinity choline uptake (HACU) by brain cholinergic neurons (7) impaired retention performance of a one-trial step-through inhibitory avoidance response in adult male CF-1 mice. This effect was observed even 7 days after the learning trial. The dose of $\mathrm{HC}-3$ used in these experiments reduces the HACU in the hippocampus by approximately $50 \%$ after 60 min of its icvadministration (10). After the completion of the retention test at each of the training-test intervals studied, the HACU in the hippocampus of the HC-3-treated mice was not significantly different from that of the control group. This apparent dissociation between neurochemistry and behavior suggests that the effects of HC-3 are probably not directly exerted on memory retrieval, and indicates that HACU inhibition took place at early stages of memory consolidation (10). These results agree with experimental and clinical evidence suggesting that brain Ach plays an essential role in mnemonic phenomena $(27,28)$.

The administration of $\mathrm{HC}-3$ produced a deleterious effect on retention only when given immediately after memory reactivation, but this effect was not observed if memory was not reactivated. The degree of vulnerability to $\mathrm{HC}-3$ administered immediately after memory reactivation changes as a function of the time elapsing between original learning and retrieval (29). Thus, recent memories (27 days old) are labile, but remote ones (14-30 days old) become progressively insensitive to HC-3 $(10,29)$ (Figure 2). Also, we did not observe spontaneous recovery 21 days after training when memory was retrieved 2 days after it and $\mathrm{HC}-3$ was given immediately after memory retrieval (29).

Some of the results seem to be in conflict with the report that scopolamine, a well-known non-specific central muscarinic cholinergic receptor antagonist, did not impair memory when given after retrieval (30). Differences in the administration route, the drug employed, the animal species, and the behavioral paradigm used may account for the discrepancies. However, our results support recent findings, which indicated that memory reconsolidation of morphine-conditioned place preference is disrupted by scopolamine (31). These findings suggest the potential benefits of pharmacological interventions directed at central cholinergic neurotransmission in order to disrupt reconsolidation of memories associated with environmental cues and addictive drugs.

Thus, for the first time, we suggested a participation of central cholinergic mechanisms in memory reconsolidation of an IAR in mice $(10,29)$.

\section{Nitric oxide}

Previous results demonstrated that the immediate posttraining intraperitoneal administration of L-NAME, a nonspecific inhibitor of NOS (8), impairs retention test perfor-

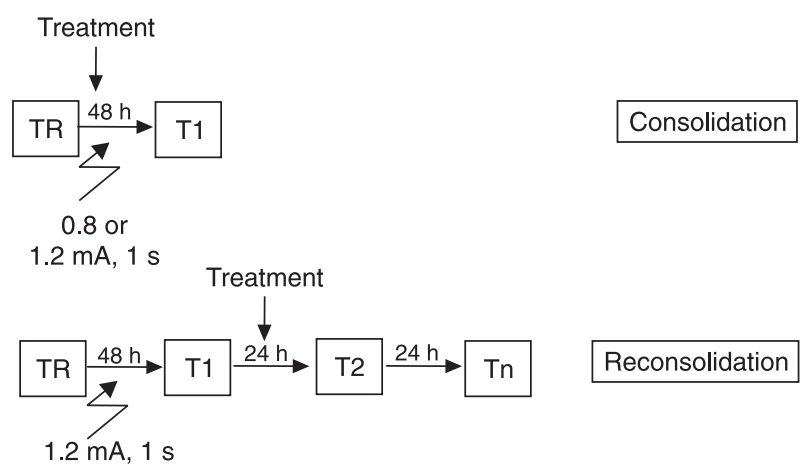

Figure 1. Behavioral scheme employed for memory consolidation and reconsolidation studies. $\mathrm{TR}=$ training; $\mathrm{T} 1=1$ st retention test; $\mathrm{T} 2=2 \mathrm{nd}$ retention test; $\mathrm{Tn}=$ successive retention tests.

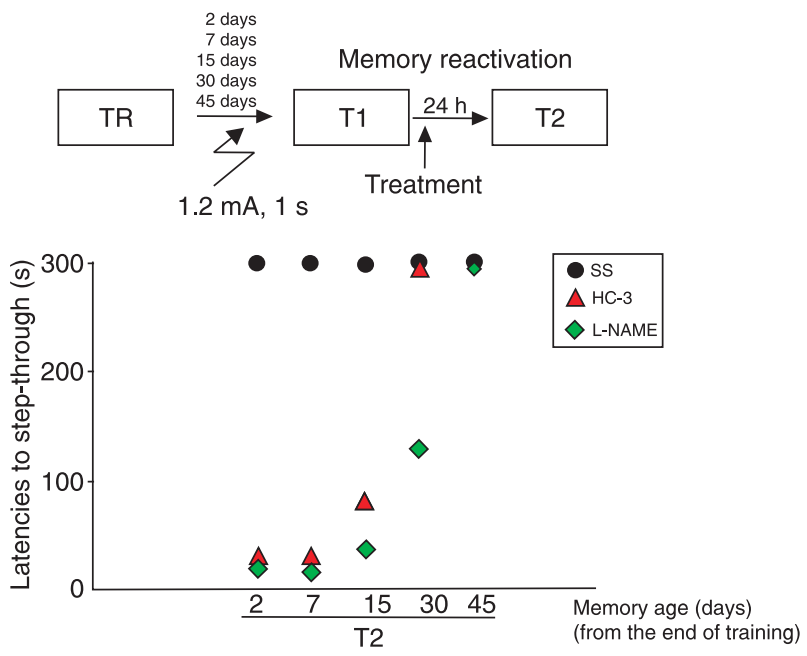

Figure 2. Time course of the effects of saline solution (SS; icv or $i p)$, hemicholinium $(\mathrm{HC}-3, i c v)$, and of $\mathrm{N}^{\omega}$-nitro-L-arginine methyl ester (L-NAME, ip) given immediately after memory reactivation. Top: behavioral scheme; TR = training; T1 = first retention test; $\mathrm{T} 2$ = second retention test. There is an inverse relation between the efficacy of the treatment on memory reconsolidation and the interval between TR and T1. 
mance (32). The effect of L-NAME on retention was attributed to an action on memory consolidation of the original learning, and was probably due to inhibition of Ach release from brain regions critically involved in memory consolidation (33).

For the first time, we also reported that the administration of L-NAME after the first retention test (reactivation) of the IAR impaired retention performance over 6 consecutive days. This effect was observed only following memory reactivation, and was dose- and time-dependent (11). Furthermore, the post-retrieval effects of L-NAME were attenuated by L-arginine, but not by $\mathrm{D}$-arginine, suggesting an action on NOS (8). The effects of L-NAME on reactivated memory could not be attributed to a retrieval deficit since a mild foot shock did not reinstate the previous response and no spontaneous recovery was observed at least 21 days after training.

The administration of L-NAME prior to the second retention test to mice that received either vehicle or LNAME immediately after the first memory reactivation does not affect memory retrieval. Thus, the concept of statedependency is not useful to explain the post-retrieval deleterious effects of L-NAME on subsequent retention test performance (11).

The impairment of retention performance caused by LNAME was dependent on the age of the reactivated memory, and was observed when the first retrieval session took place at 7, 15, or 30 days, but the effect was no longer seen when re-exposure occurred 45 days after training (11) (Figure 2).

It has been recently shown that intra-amygdala infusions of 7-nitroindazole, a more specific inhibitor of neuronal-NOS (8), or C-PTIO, a membrane impermeable scavenger of $\mathrm{NO}$, impaired consolidation, but not reconsolidation of auditory fear conditioning in rat (34). These results seems to be opposite to ours; however, again, several experimental differences could be related to these discrepancies (behavioral task, experimental subjects, injections of drugs, or the aim of the experiments among others). Differences in brain areas and mechanisms recruited after memory reactivation described by Alberini et al. (35) could explain the results of Schafe et al. (34) and ours.

Taken together, these results suggest an action of LNAME on memory reactivation-induced processes, extending the biological significance of NO on memory.

\section{Nuclear factor $\kappa B$ transcription factor}

The first evidence that links NF- $\mathrm{NB}$ family function with memory formation was obtained in the long-term memory model of the crab (an invertebrate) Chasmagnatus $(36,37)$.
Recent studies in rodents give further support to the role of $\mathrm{NF}-\kappa \mathrm{B}$ in memory (38). We studied the participation of NF$\kappa B$ in memory using the IAR, which is in part dependent on hippocampal function (39).

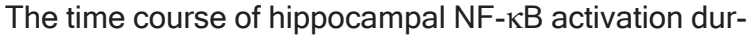
ing memory consolidation showed an inhibition of NF- $\mathrm{KB}$ 15 min after training followed by an activation peak at 45 min, returning to basal levels 2 and $4 \mathrm{~h}$ after training, in shocked and unshocked groups when compared with the naive group (12). NF- $\mathrm{BB}$ is also activated in the hippocampus by memory retrieval, and is probably involved in restabilization of the original memory, but its activation occurs earlier in memory reconsolidation than in memory consolidation: the peak of NF- $\mathrm{KB}$ activation takes place 15 min after memory reactivation (13).

The role of NF- $\kappa B$ in memory consolidation and reconsolidation was further assessed by NF- $\mathrm{KB}$ inhibition using two independent strategies: the administration of the NF$\kappa \mathrm{B}$ pathway inhibitor sulfasalazine, which acts as a direct I $\mathrm{KB}$ kinase inhibitor (40), and the use of a double-stranded DNA oligonucleotide containing the NF- $\kappa B$ consensus sequence ( $\kappa$ Bdecoy) for direct inhibition (12).

Intracerebroventricular injection of sulfasalazine immediately after training (memory consolidation) impaired retention test performance in a dose- and time-dependent manner (12). These results agree with those of Merlo et al. (40).

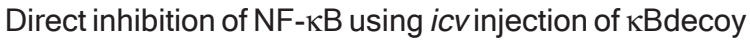
$2 \mathrm{~h}$ before training, both to shocked and unshocked mice during the learning trial, revealed a specific NF- $\kappa B$ inhibition in the hippocampus, well correlated with an impairment of long-term memory (LTM) consolidation (12). Conversely, injection of $\kappa$ Bdecoy with one base mutation (m$\kappa B d e c o y$ ) did not affect LTM, and no inhibition of NF- $\mathrm{KB}$ was found in the hippocampus.

These results suggest that activation of NF-kB in the hippocampus is part of the molecular mechanism involved in the storage of contextual features that constitute the conditioned stimulus representation (12).

The inhibition of hippocampal NF- $\kappa B$ activity after memory reactivation, using either sulfasalazine or NF-кBdecoy, impairs LTM only when applied immediately after the retention test, but not if delayed $3 \mathrm{~h}$ after memory retrieval, indicating a transient time-window of memory susceptibility. The impairment was not observed when the re-exposure to the training context was omitted, indicating, again, that memory retrieval is necessary to open a new timewindow of susceptibility of a reactivated memory, and suggesting an effect of NF-KB inhibition on memory reconsolidation. Short-term memory was not affected by post-retrieval intra-hippocampal injections of $\kappa$ Bdecoy, whereas its effect on LTM persisted for more than 3 weeks, 
without signs of spontaneous recovery (13).

Taken together, the results discussed in this section suggest that NF- $\kappa B$ is an important transcriptional regulator in memory consolidation and reconsolidation in the hippocampus, although the kinetics of activation differs between the two amnesic processes.

\section{Non-pharmacological manipulations: a new learning task}

The aim of these experiments was to test if a more physiological approach such as exposure to a new different learning task, instead of a pharmacological tool, could retrogradely affect memory consolidation and/or memory reconsolidation of the inhibitory avoidance task. Inhibitory avoidance was performed as described in the preceding sections, except that in both memory consolidation and reconsolidation studies, mice were over-reinforced on the learning trial. A single session of 5-min exposure to a hole-board (nosepoke behavior) (41) was used as a potential different learning task (14). Under these experimental conditions, we observed that the exposure to the hole-board, either immediately after training or after the first retention test, impaired retention performance for two consecutive days. In both situations, the effects were time-dependent. Only the mice that were exposed once to the hole-board, either immediately after the avoidance learning or after the first retention test, exhibited a poor avoidance retention performance. On the contrary, in mice that were previously habituated to the nose-poke task before the avoidance learning, a re-exposure to the apparatus, either immediately after the avoidance training or immediately after memory reactivation, did not affect subsequent retention performance during any test session. Thus, the acquisition of the habituation response appears to be determinant for the amnestic effect caused by the hole-board. Mere exposure to the hole-board without a memory reactivation session did not affect performance, suggesting a lack of non-specific effect of the hole-board task. At first glance, the results are consistent with an interference of the new learning with memory reconsolidation of the original learning $(42,43)$.

Post-retrieval effects of a new learning on retention performance of the IAR were prevented in mice receiving a low dose of scopolamine, a non-specific muscarinic receptor blocker, which blocks the acquisition of new learning, before being exposed to the hole-board apparatus (Blake MG, Boccia MM, Baratti CM, unpublished data).

\section{General discussion}

In the present paper, we review recent data from our laboratory, which indicated that three different pharmacological treatments ( $\mathrm{HC}-3$, inhibition of NF- $\kappa B$, and L-NAME), and a non-pharmacological one (a new learning situation) impaired retention performance of an IAR in mice when applied either after training (memory consolidation) or after retrieval (memory reconsolidation). All treatments negatively affected long-term memory of the original avoidance learning.

The effects of the post-retrieval treatments employed appear to be a consequence of a true blockade of reconsolidation processes, and not of those that mediate memory extinction, because mice did not show spontaneous recovery, reinstatement or renewal $(11,13,15,29)$. In addition, the state-dependency phenomenon was not observed (11). Taken together, the results agree with the storage deficit hypothesis of a reactivated memory (1) in order to explain the post-retrieval effects of different "treatments" on retention performance of an IAR.

All the treatments reviewed here produced a deleterious effect on retention only when given immediately after memory reactivation, and were not observed if memory was not reactivated. The degree of vulnerability of memories changes as a function of the time elapsing between original learning and retrieval (29). Thus, recent memories (2-7 days old) are labile, but remote ones (14-45 days old) become progressively insensitive to the treatment $(10,29)$ (Figure 2).

In most studies with diverse animal species, memory reconsolidation is demonstrated by pharmacological manipulations of reactivated memories $(16,22,44)$, including those described here. The interferences of reactivated memories through more "physiological" approaches were also described by Walker et al. (45), Hupbach et al. (46), and more recently by Forcato et al. (47). All these studies were performed in humans. The demonstration by Forcato et al. (47) that the process of memory reconsolidation also occurs with declarative memory in humans is significant not only by itself, but also due to the original behavioral study performed.

An extensive body of evidence has been gathered either in favor of or against memory reconsolidation. In this review we will not discuss the effect of protein synthesis inhibitors on memory reconsolidation since they are beyond the scope of the present report and were recently extensively reviewed (48).

Several transcription factors have been implicated in memory reconsolidation. The roles of CREB, ELK1 and $\mathrm{NF}-\kappa \mathrm{B}$ in reconsolidation are consistent with their previously demonstrated role in the initial consolidation of memory. Differences in the temporal requirements for consolidation and reconsolidation have been described in other 
models (35). Lee et al. (49) reported that antisense-mediated disruption of the transcription factor zinc finger (zif268) in the rat hippocampus impairs reconsolidation but not consolidation of contextual fear conditioning, whereas, conversely, antisense-mediated disruption of brain-derived neurotrophin factor impairs consolidation but not reconsolidation, suggesting that the molecular mechanisms required by the hippocampus during either consolidation or reconsolidation are distinct. This line of evidence showed that the disruption of C/EBP $\beta$, known as a fundamental molecular pathway required for memory consolidation, by injection of specific antisense oligodeoxynucleotides ( $\beta$ ODNs) in the hippocampus, impairs long-term memory of inhibitory avoidance in rats (50). In contrast, when injected immediately after memory reactivation it has no effect on memory retention tested 2 days later. Interestingly, $\mathrm{C} /$ EBP $\beta$ seems to play an opposite role in the amygdala when compared with that found in the hippocampus. $\beta$ ODN injections into the basolateral amygdala disrupt reconsolidation but not the consolidation of an inhibitory avoidance (35). Taken together, these results suggest that consolidation differs from reconsolidation by recruiting different brain regions and molecular targets. However, it does not rule out the possibility that in other brain regions both processes engage common molecular pathways.

\section{References}

1. Dudai $Y$, Eisenberg M. Rites of passage of the engram: reconsolidation and the lingering consolidation hypothesis. Neuron 2004; 44: 93-100.

2. McGaugh JL. Memory - a century of consolidation. Science 2000; 287: 248-251.

3. Davis HP, Squire LR. Protein synthesis and memory: a review. Psychol Bull 1984; 96: 518-559.

4. Canal CE, Chang Q, Gold PE. Amnesia produced by altered release of neurotransmitters after intraamygdala injections of a protein synthesis inhibitor. Proc Natl Acad Sci U S A 2007; 104: 12500-12505.

5. Squire LR, Alvarez P. Retrograde amnesia and memory consolidation: a neurobiological perspective. Curr Opin Neurobiol 1995; 5: 169-177.

6. Przybyslawski J, Roullet P, Sara SJ. Attenuation of emotional and nonemotional memories after their reactivation: role of beta adrenergic receptors. J Neurosci 1999; 19: 6623-6628.

7. Gardiner JE. The inhibition of acetylcholine synthesis in brain by a hemicholinium. Biochem J 1961; 81: 297-303.

8. Alderton WK, Cooper CE, Knowles RG. Nitric oxide synthases: structure, function and inhibition. Biochem J 2001; 357: 593-615.

9. Romano A, Freudenthal R, Merlo E, Routtenberg A. Evolutionarily-conserved role of the NF-kappaB transcription factor in neural plasticity and memory. Eur J Neurosci 2006;
Recently, brain-derived neurotrophin factor was reported as an important neurotrophic factor implicated in memory persistence (51), suggesting that different waves of protein synthesis are implicated in different stages of memory formation (see also Ref. 52).

There are several parametric conditions for reconsolidation, two of them already mentioned: the age of the memory (that is, time since training) and the strength of the memory or the amount of training. Another one that deserves attention is the length of the reactivation trial. All of them are important determinants of whether reconsolidations of extinction occur after a memory reactivation test. Identifying the molecular mechanism that changes as a result of age, memory strength and length of reactivation will allow an objective determination of what underlies a boundary condition of memory reconsolidation.

Temporal constraints on the fragility of memories to post-reactivation interventions, in particular those that lead to amnesia of the original memory $(18,53,54)$ have led some investigators to propose that reconsolidation may be explained as a prolonged phase of consolidation $(1,22)$. Our results may be in accordance with this last interpretation, but further research is necessary in order to elucidate subtle behavioral differences between memory consolidation and reconsolidation.
24: 1507-1516.

10. Boccia MM, Acosta GB, Blake MG, Baratti CM. Memory consolidation and reconsolidation of an inhibitory avoidance response in mice: effects of i.c.v. injections of hemicholinium-3. Neuroscience 2004; 124: 735-741.

11. Baratti CM, Boccia MM, Blake MG, Acosta GB. Reactivated memory of an inhibitory avoidance response in mice is sensitive to a nitric oxide synthase inhibitor. Neurobiol Learn Mem 2008; 89: 426-440.

12. Freudenthal R, Boccia MM, Acosta GB, Blake MG, Merlo E, Baratti CM, et al. NF-kappaB transcription factor is required for inhibitory avoidance long-term memory in mice. Eur $J$ Neurosci 2005; 21: 2845-2852.

13. Boccia M, Freudenthal R, Blake M, de la Fuente V, Acosta $\mathrm{G}$, Baratti C, et al. Activation of hippocampal nuclear factorkappa $\mathrm{B}$ by retrieval is required for memory reconsolidation. J Neurosci 2007; 27: 13436-13445.

14. Boccia MM, Blake MG, Acosta GB, Baratti CM. Memory consolidation and reconsolidation of an inhibitory avoidance task in mice: effects of a new different learning task. Neuroscience 2005; 135: 19-29.

15. Gold PE. The use of avoidance training in studies of modulation of memory storage. Behav Neural Biol 1986; 46: 8798.

16. Tronson NC, Taylor JR. Molecular mechanisms of memory reconsolidation. Nat Rev Neurosci 2007; 8: 262-275. 
17. Duvarci S, Nader K. Characterization of fear memory reconsolidation. J Neurosci 2004; 24: 9269-9275.

18. Milekic $\mathrm{MH}$, Alberini $\mathrm{CM}$. Temporally graded requirement for protein synthesis following memory reactivation. Neuron 2002; 36: 521-525.

19. Pavlov IF. Conditioned reflexes. London: Oxford University Press; 1927.

20. Bouton ME. Context and behavioral processes in extinction. Learn Mem 2004; 11: 485-494.

21. Alberini CM. Mechanisms of memory stabilization: are consolidation and reconsolidation similar or distinct processes? Trends Neurosci 2005; 28: 51-56.

22. Alberini CM. Reconsolidation: The Samsara of memory consolidation. Deb Neurosci 2007; 1: 17-24.

23. Tinsley MR, Quinn JJ, Fanselow MS. The role of muscarinic and nicotinic cholinergic neurotransmission in aversive conditioning: comparing Pavlovian fear conditioning and inhibitory avoidance. Learn Mem 2004; 11: 35-42.

24. Duran-Arevalo M, Cruz-Morales SE, Prado-Alcala RA. Is acetylcholine involved in memory consolidation of over-reinforced learning? Brain Res Bull 1990; 24: 725-727.

25. Rescorla RA. Spontaneous recovery. Learn Mem 2004; 11: 501-509.

26. Izquierdo I. Different forms of post-training memory processing. Behav Neural Biol 1989; 51: 171-202.

27. Power AE, Vazdarjanova A, McGaugh JL. Muscarinic cholinergic influences in memory consolidation. Neurobiol Learn Mem 2003; 80: 178-193.

28. Decker MW, McGaugh JL. The role of interactions between the cholinergic system and other neuromodulatory systems in learning and memory. Synapse 1991; 7: 151-168.

29. Boccia MM, Blake MG, Acosta GB, Baratti CM. Post-retrieval effects of $i c v$ infusions of hemicholinium in mice are dependent on the age of the original memory. Learn Mem 2006; 13: 376-381.

30. Bucherelli C, Baldi E, Mariottini C, Passani MB, Blandina P. Aversive memory reactivation engages in the amygdala only some neurotransmitters involved in consolidation. Learn Mem 2006; 13: 426-430.

31. Zhai H, Wu P, Chen S, Li F, Liu Y, Lu L. Effects of scopolamine and ketamine on reconsolidation of morphine conditioned place preference in rats. Behav Pharmacol 2008; 19: 211-216.

32. Baratti CM, Kopf SR. A nitric oxide synthase inhibitor impairs memory storage in mice. Neurobiol Learn Mem 1996; 65: 197-201.

33. Kopf SR, Baratti CM. Enhancement of the post-training cholinergic tone antagonizes the impairment of retention induced by a nitric oxide synthase inhibitor in mice. Neurobiol Learn Mem 1996; 65: 207-212.

34. Schafe GE, Bauer EP, Rosis S, Farb CR, Rodrigues SM, LeDoux JE. Memory consolidation of Pavlovian fear conditioning requires nitric oxide signaling in the lateral amygdala. Eur J Neurosci 2005; 22: 201-211.

35. Alberini CM, Milekic MH, Tronel S. Mechanisms of memory stabilization and de-stabilization. Cell Mol Life Sci 2006; 63: 999-1008.

36. Tomsic D, Pedreira ME, Romano A, Maldonado H. ContextUS association as a determinant of long-term habituation in the crab Chasmagnathus. Anim Learn Behav 1998; 26: 196-209.
37. Freudenthal R, Romano A. Participation of Rel/NF-kappaB transcription factors in long-term memory in the crab Chasmagnathus. Brain Res 2000; 855: 274-281.

38. Yeh SH, Lin $\mathrm{CH}$, Lee CF, Gean PW. A requirement of nuclear factor-kappaB activation in fear-potentiated startle. J Biol Chem 2002; 277: 46720-46729.

39. Izquierdo I, Quillfeldt JA, Zanatta MS, Quevedo J, Schaeffer E, Schmitz PK, et al. Sequential role of hippocampus and amygdala, entorhinal cortex and parietal cortex in formation and retrieval of memory for inhibitory avoidance in rats. Eur J Neurosci 1997; 9: 786-793.

40. Merlo E, Freudenthal R, Romano A. The IkappaB kinase inhibitor sulfasalazine impairs long-term memory in the crab Chasmagnathus. Neuroscience 2002; 112: 161-172.

41. Boccia MM, Baratti CM. Effects of oxytocin and an oxytocin receptor antagonist on retention of a nose-poke habituation response in mice. Acta Physiol Pharmacol Ther Latinoam 1999; 49: 155-160.

42. Spear N. Retrieval of memory in animals. Psychol Rev 1973; 80: 163-194.

43. Sara SJ. Retrieval and reconsolidation: toward a neurobiology of remembering. Learn Mem 2000; 7: 73-84.

44. Da Silva WC, Bonini JS, Bevilaqua LR, Medina JH, Izquierdo I, Cammarota M. Inhibition of mRNA synthesis in the hippocampus impairs consolidation and reconsolidation of spatial memory. Hippocampus 2008; 18: 29-39.

45. Walker MP, Brakefield T, Hobson JA, Stickgold R. Dissociable stages of human memory consolidation and reconsolidation. Nature 2003; 425: 616-620.

46. Hupbach A, Gomez R, Hardt O, Nadel L. Reconsolidation of episodic memories: a subtle reminder triggers integration of new information. Learn Mem 2007; 14: 47-53.

47. Forcato C, Burgos VL, Argibay PF, Molina VA, Pedreira ME, Maldonado $\mathrm{H}$. Reconsolidation of declarative memory in humans. Learn Mem 2007; 14: 295-303.

48. Alberini CM. The role of protein synthesis during the labile phases of memory: revisiting the skepticism. Neurobiol Learn Mem 2008; 89: 234-246.

49. Lee JL, Everitt BJ, Thomas KL. Independent cellular processes for hippocampal memory consolidation and reconsolidation. Science 2004; 304: 839-843.

50. Taubenfeld SM, Milekic MH, Monti B, Alberini CM. The consolidation of new but not reactivated memory requires hippocampal C/EBPbeta. Nat Neurosci 2001; 4: 813-818.

51. Bekinschtein $P$, Cammarota $M$, Igaz LM, Bevilaqua LR, Izquierdo I, Medina JH. Persistence of long-term memory storage requires a late protein synthesis- and BDNF-dependent phase in the hippocampus. Neuron 2007; 53: 261277.

52. Wanisch K, Wotjak CT. Time course and efficiency of protein synthesis inhibition following intracerebral and systemic anisomycin treatment. Neurobiol Learn Mem 2008; 90: 485494.

53. Suzuki A, Josselyn SA, Frankland PW, Masushige S, Silva AJ, Kida S. Memory reconsolidation and extinction have distinct temporal and biochemical signatures. $J$ Neurosci 2004; 24: 4787-4795.

54. Frankland PW, Ding HK, Takahashi E, Suzuki A, Kida S, Silva AJ. Stability of recent and remote contextual fear memory. Learn Mem 2006; 13: 451-457. 